\title{
The effects of a 12-week program of static upper extremity weight bearing exercises on weight bearing in children with hemiplegic type of cerebral palsy
}

\begin{abstract}
The major objective of this study was to quantify the effects of a 12-week program of weight bearing exercises on weight borne through the hand and grip pressures in children with hemiplegic cerebral palsy. This study also sought to monitor the change in spasticity immediately following weightbearing exercises. A quasi-experimental, one group pre-test, post-test study was used. Eleven children with hemiplegic type of cerebral palsy from a special school in KwaZulu Natal participated after fully informed written consent. The intervention consisted of a 12-week program of weight bearing. The Tekscan Grip system was used to quantify weight borne through the hand during extended arm prone and quadruped positions and whilst holding a pencil and a tumbler. The modified Ashworth grading of spasticity was used to monitor spasticity. The data was analysed using the random effects GLS model Wald Chi Square test. Significant increases in contact pressure in extended arms prone $(p=0,012)$ and quadruped $(p=0,002)$ and when holding a pencil $(p=0,045)$ was noted post-test compared to pre-test. Significant increases in contact area of the hand was also noted in prone ( $p=0,000)$, quadruped ( $p=0,03$ at assessment 7$)$ and when holding a pencil $(p=0,035)$. A significant decrease in spasticity during elbow extension $(p=0,004)$, and wrist flexion ( $p=0,026)$ and extension $(p=0,004)$ was noted. An overall significant effect of static weight bearing exercises on weight borne through the hands, grip strength and spasticity justifies the use of static weight-bearing in therapy.
\end{abstract}

KEY WORDS: CEREBRAL PALSY, HEMIPLEGIA, HAND CONTACT PRESSURE, CONTACT AREA, STATIC WEIGHT-BEARING EXERCISES.

\section{Introduction}

The upper extremity plays an integral role in an individual's ability to interact with the environment. In patients with cerebral palsy, spastic paresis, ataxia, dyskinesia, impaired sensation, visual and auditory disturbances impair upper extremity function. It is reported that almost $50 \%$ of patients with cerebral palsy have impaired arm-hand function resulting in limitations in activities and restrictions in participation (Van Meeteren et

\section{Correspondence to:}

T. Puckree

Department of Physiotherapy,

University of KwaZulu Natal

Private Bag X54001

Durban

4001

Email: puckreet@ukzn.ac.za al 2007, Odding et al 2006, Fedrizzi et al 2003, Beckung and Hagberg 2002). It is clear that spasticity and decreased muscle strength especially of the agonists are significant in promoting the impairments of upper extremity function observed (Pin 2007, van Meeteren et al 2007, Bovend'Eerdt 2008). Various treatment approaches, namely functional electrical stimulation, constraint induced therapy, strength training, biofeedback, and Neurodevelopmental Therapy (NDT) have been used to manage upper limb dysfunction in children with Cerebral Palsy (CP). Although the concept and application of NDT principles has evolved, one of the original tenets of this approach was based on the fact that movement through the various developmental stages prepares the child for stability followed by mobility (Bobath and Bobath 1980). To support this, weight bearing in different positions had been identified as a tool because it helps to reduce spasticity and improve function (Davis 1985, Chakerian and Larson 1993, Gracies 2001). Developmentally, weight bearing through progressively decreasing the base of support develops balance and function. Physiologically sustained stretch through static weight bearing inhibits activity of muscles spindles thereby reducing spasticity (Smelt 1989, Gracies 2001, Pin 2007). The overall evidence for the clinical effect of stretching on spasticity is inconclusive (Bovend'Eerdt et al 2008). These researchers did not include studies that looked at weight-bearing as a stretching technique in their systematic review of the effects of stretching on spasticity.

Although some research has been conducted on grip strength (Hallam and Weindling 1998, van Meeteren 
et al 2007) and functional abilities (van Meeteren et al 2007, Smelt 1989, Kinghorn and Roberts 1996) in young adults and children with cerebral palsy, the quantification of the actual weight borne through the upper extremity during or after therapy has received little attention in the literature (Pin 2007). Information on weight taken through the upper extremities in neurologically impaired patients can provide valuable information about the plastic changes occurring in sensory and motor systems.

Smelt (1989) and Kinghorn and Roberts (1996) who investigated the effects of weight bearing splints on hand function found a reduction in tone and improvement in upper extremity function. Static weight bearing exercises are believed to stimulate antigravity muscle strength and endurance and reduce spasticity (Pin 2007). Some evidence shows that weight-bearing positions enhance feeding especially in the speed of completing the task (Noronha et al 1995). Despite all these claims, it is not known whether weight was indeed taken through the hands, and if it was then how much weight was taken.

Chakerian and Larson (1993) who undertook computerized calculations of hand surface area before and after weight bearing found an increase in the functional surface area. Chad et al (1999) found an increase in bone mineral density following weight-bearing exercises. None of the research reported in the literature quantified weight bearing through the upper extremities.

The variations in the presentations of and response to therapy of children with cerebral palsy (van Meeteren et al 2007) makes it very difficult to quantify either weight bearing through the upper extremity or the effects of weight bearing exercises (Pin 2007). van Meeteren et al (2007) found a strong correlation between maximal grip strength and functional activities of the hand. The purpose of the current study was to quantify weight bearing through the hand through monitoring pressure, force and area of contact through the hand of cerebral palsy children using a grip device and monitor changes in tone using the modified Ashworth scale after a program of static weight bearing exercises. We specifically wanted to see if weight was borne through the hands during the static weight bearing exercises. In addition if weight was taken through the hands, did the amount of weight taken improve as the children continued with the program of exercises? As an addition spasticity was monitored.

\section{Methods}

A quasi experimental, single group pretest, post-test longitudinal study was undertaken. Participants were identified from 2 of 3 schools that cater for children with cerebral palsy, in one subdistrict in KwaZulu Natal. The choice of schools was based on numbers and types of cerebral palsy in their registers. Ethical approval to conduct the study was obtained from the Biomedical Research Ethics Committee of the University of KwaZulu Natal. Permission was also obtained from the Department of Education and the principals of two schools, which had sufficient numbers of children who met the inclusion criteria to conduct both the pilot and the main study as, estimated by a statistician. For inclusion in the study the children had to be between five to 15 years of age, present with hemiplegic distribution of symptoms (assessed by therapist and diagnosed by the paediatrician), be able to follow instructions, well on the day of testing, and be willing to participate in the study. Children were excluded if they were due to undergo any surgical intervention during the study period or underwent any surgical intervention a month prior to the study (none of the participants had undergone surgery prior to the study), due to receive Botox injections during or prior to the study, if they had uncontrolled epilepsy, began any medication that had an effect on the central nervous system, had any contractures or deformities in the upper extremity, had associated Attention Deficit Hyperactive Syndrome or had total cortico-visual impairment.

\section{Instrumentation}

The Grip System (Tekscan Inc.) was used to measure weight bearing. The Grip System recorded the dynamic pressure and force applied by the hand during weight-bearing and grasping objects. The system included sensors that were attached to each finger of the hand through the use of a glove (Figure 1).

Each sensor records individually but the output is the average of all the sensor readings for a period of 8 seconds. Specific variables monitored included contact pressure in pounds per square inch (psi)/seconds which reflected weight

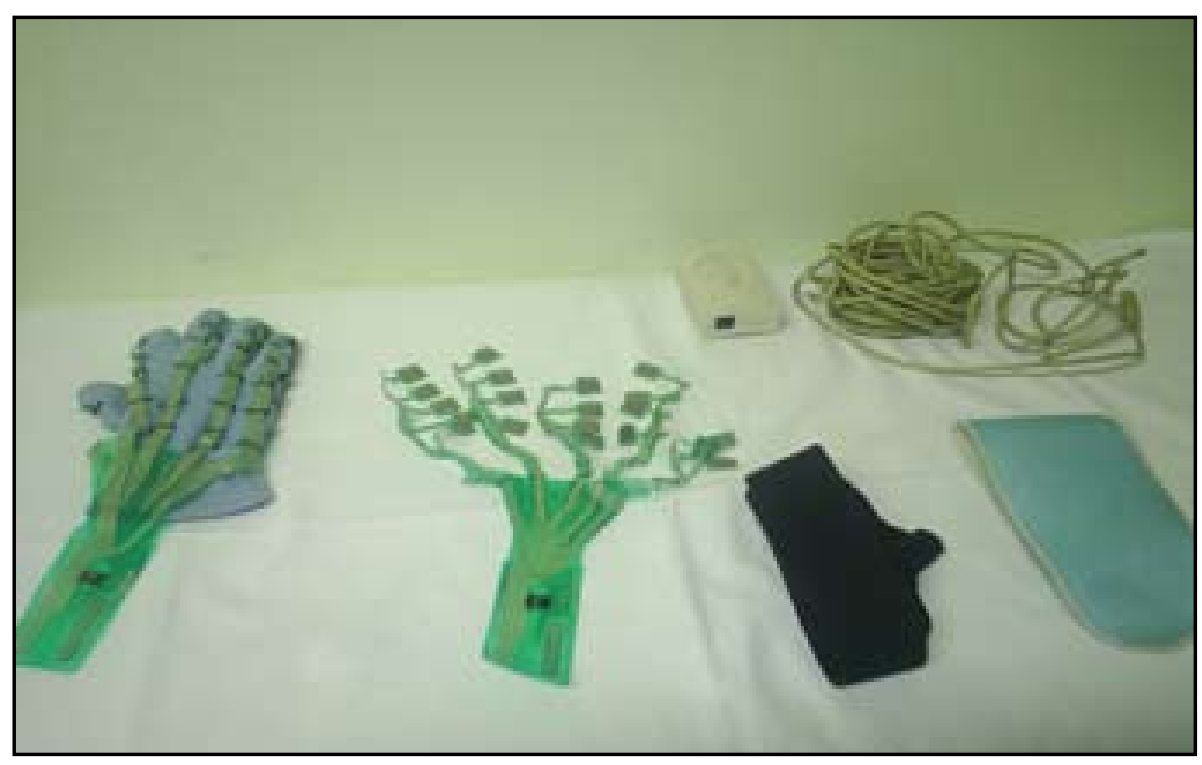

Figure 1: Photograph of grip system consisting of the sensors, cuff unit, straps and the connecting cable 
bearing through the hands, contact area in inches squared, force exerted per second (mean obtained), peak force and peak pressure. The grip system has an internal validity test, which allows for calibration prior to use. The test-retest reliability was established by conducting assessments on two normal subjects and on two children with cerebral palsy who were not a part of the main study. The results were not analysed, just inspected for consistent outcomes and minimal measurement error (less than two percent). Weight bearing and grip force measures were taken at intervals of 14 days to determine exactly when changes occurred.

The modified Ashworth grading of spasticity was used to monitor spasticity (O' Sullivan and Schmitz, 2001). The reliability of the scale was confirmed by Bohannon and Smith (1987). Recent evidence suggests that even though the Ashworth Scale is widely used in clinical and research work, its validity and reliability is questionable (Fleuren et al 2010). No other suitable scale to measure spasticity has been proposed in the literature. The grading of spasticity was done at pre-intervention and again immediately after completion of the treatment programme for all the children which was after 12 weeks.

To increase reliability, all the assessments throughout the study were conducted by the same researcher (the first author) with the exception of the grading of spasticity. In order to maintain objectivity, the Head of the Physiotherapy Department at the special school assessed spasticity in all children. The assessor was blinded to the purpose of the study to eliminate bias.

For the Grip System assessment a cloth covered plank with the sensors placed on the surface where the child could place his/her hand when assuming the weight bearing position was used. The child was asked to wash his/her hand in a diluted antiseptic solution (Savlon) and wipe the hands prior to commencing the assessment to prevent any cross contamination. Weight bearing on extended arms was monitored in two weight bearing positions namely, quadruped and prone and two functional positions namely holding a pencil and a tumbler. These two positions were chosen because all the children could maintain them without many compensatory movements or the assistance of the researcher.

Each child placed the affected hand on the sensor and the other hand parallel to the affected hand when assuming each of the two positions. Each child maintained the position for eight seconds while the force exerted was recorded. If the child could not maintain the trunk in the prone with extended arms position without support, a prone wedge was used under the chest to support the child without interference to the weight bearing. The child then sat on a chair whose seat height was sufficient to allow the child's feet to rest comfortably on the floor with the hips and knees at $90^{\circ}$. Each child then either used a glove fitted with sensors or had the sensors directly attached to the hand if spasticity prevented the child from wearing the glove, to hold the pencil and glass. The sensors were attached to the glove as per the instructions in the Tekscan manual. If the sensors were attached directly on the hand, a commercially available adhesive tape, (Micropore, 12mm x 10m), dressing tape was used to secure it in place. The sensor tab was placed on the dorsal surface and the connecting traces were wrapped around the fingers. The active regions were positioned between the joints of a finger. In the palm, sensors were placed on the thenar and hypothenar eminences and along the $2^{\text {nd }}$ to the $4^{\text {th }}$ metacarpal heads. The sensors (Figure 1) were placed in the same position at every measurement using bony landmarks as a guide.

Each child was asked to hold the pencil as if he/she was about to write but instructed not to rest the hand on any surface or hold it against the chest wall. The majority of the children displayed a predominant spastic upper limb flexor pattern. Each child was allowed to hold the pencil/glass in the pattern that she or he found comfortable. The child first held the pencil until the recording was done (eight seconds) and then after a minute held the tumbler.
Intervention program (Jayaraman and Puckree 2010): A program of weight bearing was undertaken by each child three times a week, for 15 minutes, for 12 weeks under supervision of the researcher. The program of ten static weight bearing exercises (Figure 2) included prone lying weight-bearing on forearms over a prone wedge, and on hands over a prone wedge, prone lying weight bearing on forearms over a bolster/roller and on hands (extended elbows) over a bolster, quadruped position, quadruped with unaffected hand resting on a table, side sitting weight bearing on affected hands, prone lying weight bearing on hands on a flat stool, on an inclined stool, and on hands over a ball. Each position was demonstrated to the child before he or she had to maintain the position for 30 seconds in three rounds. The static exercises were chosen to progressively increase the amount of weight borne through the hands.

\section{Data Analysis}

When the force on an object is applied over a surface area it is referred to as the pressure exerted (http://en.wikipedia. org/wiki/Muscle). Contact pressure through the hands recorded as pounds per square inch (psi)/second allowed for the monitoring of weight bearing through the hands. Pressure or grip variables included, contact area, peak pressure and mean force borne through the hands. To normalize the data to reduce variability, each child's pre-test data served as his/her own control and percentage change from this value was calculated. Pre-test 1 was compared with the post-test. The GLS random effects model Wald Chi square test was used to compare pre-test with post-test values because the sample size was small and the data did not have a normal distribution. The Wald Chi square test is a variation of the Chi square test to accommodate analysis of data that do not have a normal distribution. The Wilcoxon Rank sum test was used to compare pre and post- intervention elbow flexor and extensor and wrist flexor and extensor tone. Significance was set at $\mathrm{p}<0,05$ 


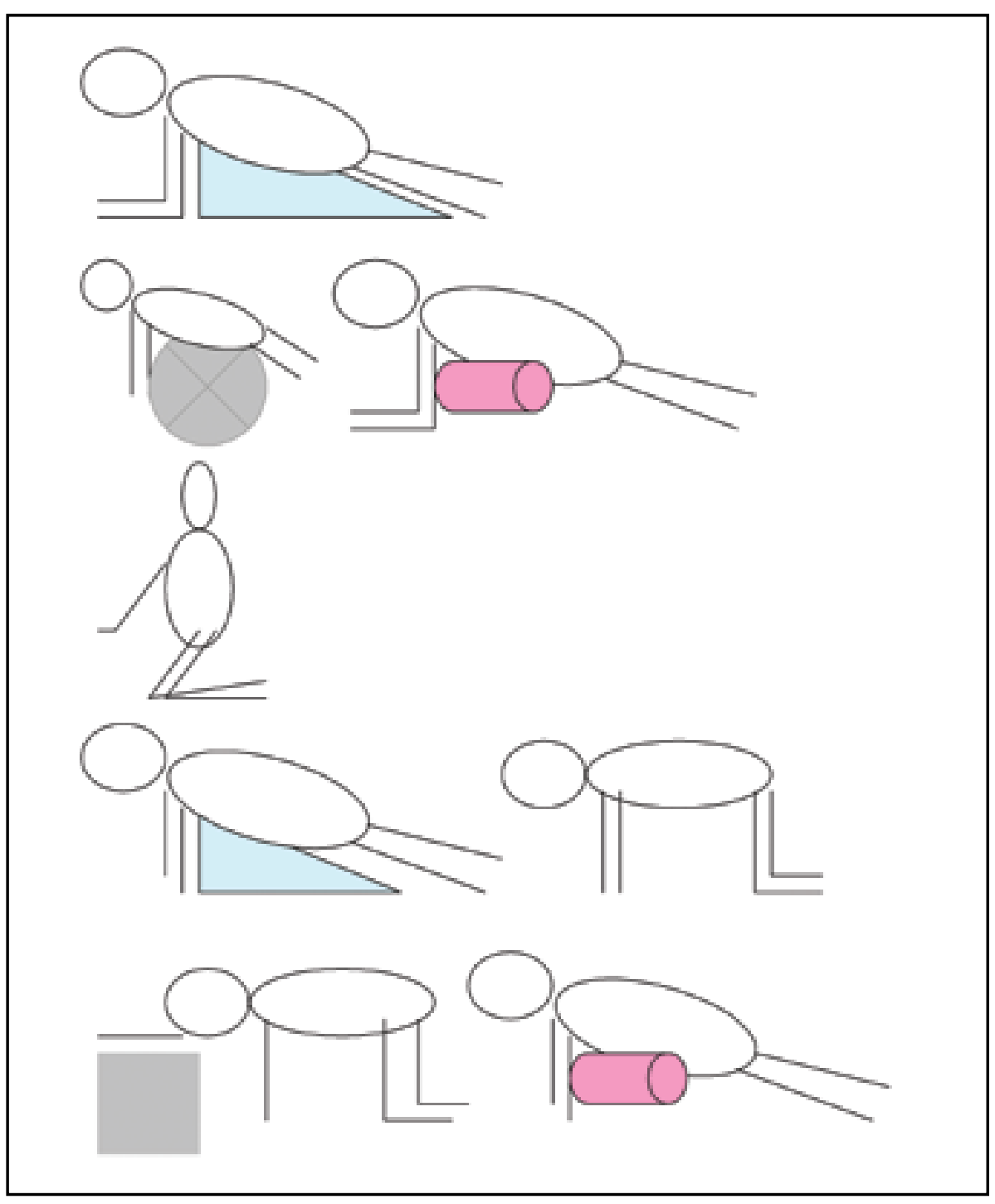

Figure 2: Eight of the 10 static weight-bearing exercises are schematically shown

Table 1: Demographic details of the participants

\begin{tabular}{|l|l|l|l|l|}
\hline Child & Gender & Side Affected & Age & Severity of condition \\
\hline A & Male & Right & $14 \mathrm{yrs}$ & Mild \\
\hline B & Male & Right & $12 \mathrm{yrs}$ & Mild \\
\hline C & Female & Right & $14 \mathrm{yrs}$ & Mild \\
\hline D & Female & Left & $14 \mathrm{yrs}$ & Mild \\
\hline E & Male & Right & $13 \mathrm{yrs}$ & Mild \\
\hline F & Male & Left & $9 \mathrm{yrs}$ & Moderate \\
\hline G & Male & Right & $12 \mathrm{yrs}$ & Moderate \\
\hline H & Male & Right & $12 \mathrm{yrs}$ & Moderate \\
\hline I & Male & Right & $12 \mathrm{yrs}$ & Severe \\
\hline J & Male & Right & $15 \mathrm{yrs}$ & Severe \\
\hline K & Male & Left & $15 \mathrm{yrs}$ & Severe \\
\hline
\end{tabular}

\section{Results}

Only eleven African (nine males and two females) children aged eight to 15 years (mean $=12.7$ years) met the inclusion criteria and participated in the study (Table 1). The right side was affected in nine children and the left side in three children. Five children presented as mild, three as moderate and four as severe according to the Bohannon and Smith (1987) classification as this was the preferred classification at the time of the study.

The data from all the 11 children who participated were usable. No emotional or other outbursts or stress were displayed by any of the children during either intervention or testing. The one problem that interfered with data collection was the school vacation. The investigator had to implement the intervention program to the convenience of the child/caregiver within the study parameters. Although no home program was included, caregivers were asked about anything that had occurred between treatment sessions.

\section{Contact pressure (psi /second)}

Contact pressure (psi/sec) in quadruped and prone positions was used to indicate the change in weight-bearing through the hands. The individual $(\mathrm{n}=11)$ and mean normalized values for contact pressure in quadruped ( $\mathrm{n}=11$ and mean) are shown in Figure 3. Variations in contact pressure between and within children over the duration of the study can be seen. In nine children the post-test values were higher than pre-test values.

On comparing pre-test values with the values at assessment 7 , the pressure exerted at the end of the treatment doubled in five children and increased in six children. Assessment 7 values dropped on post-test measurement in five children and were higher in four children (suggests variations which could be due to fluctuations in tone). Even with normalization of the data the variation as seen by the standard deviation is still high. The mean contact pressure increased significantly $(\mathrm{p}=0,002)$ from 100 (pre-test) to $162 \%$ (post-test). Contact pressure in the prone position is shown in Figure 4.

As shown in Figure 4 contact pressures in prone with extended upper limbs 


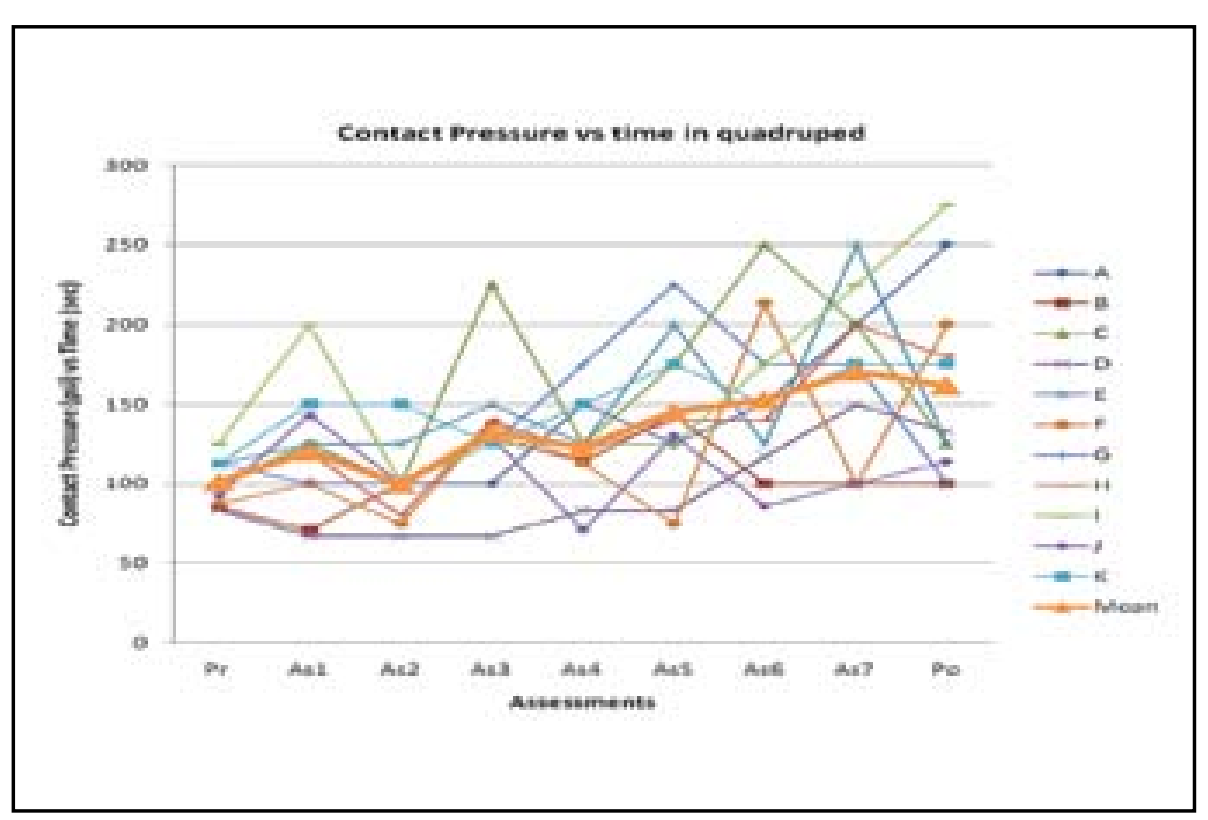

Figure 3: Normalized values of Contact pressure (psi) vs time (sec) for the sample in quadruped

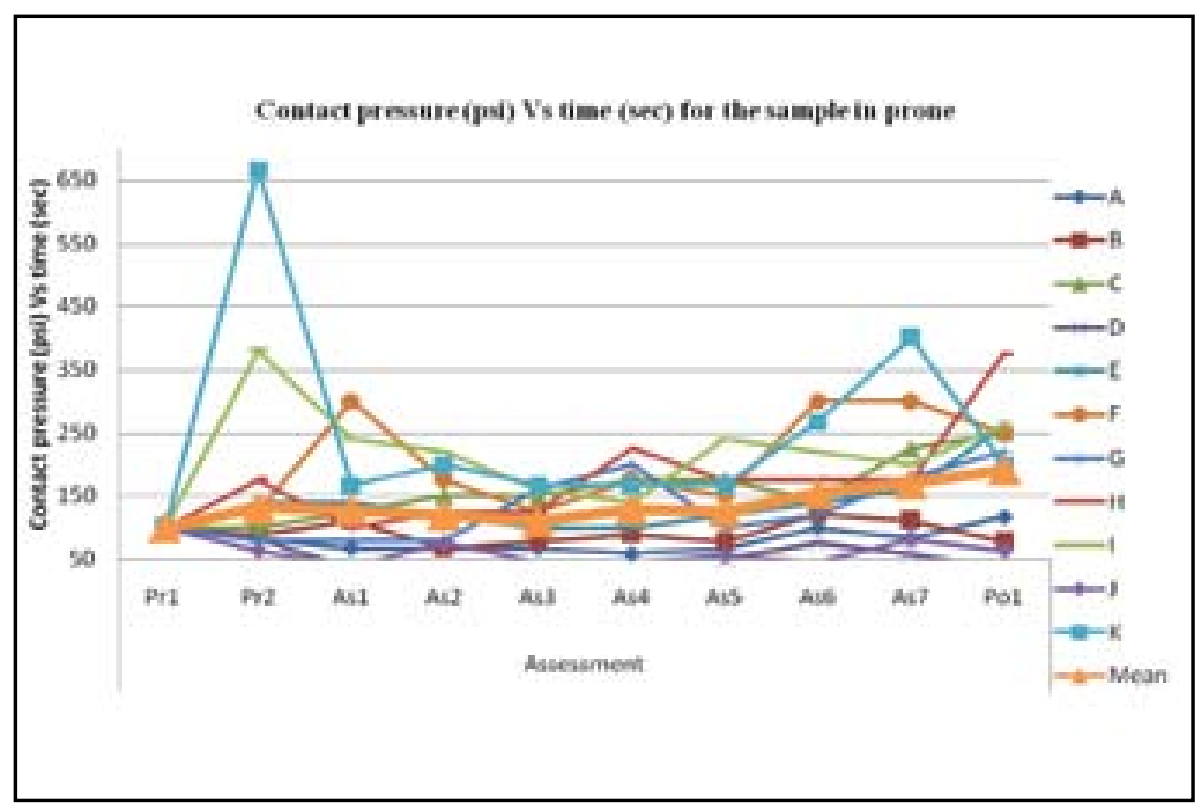

Figure 4: Contact pressure vs. time (sec) for the sample in prone

also shows inter-subject and intrasubject variability. Individual subject data did not stabilize although an upward trend can be seen in most cases. While the mean showed a significant increase from pre-test to post-test, again variability was observed over 10 measurements. Significant increases posttest compared to pre-test $(\mathrm{p}=0,012)$ were observed.
Grip system variables when holding a pencil

All 11 children could grasp and hold a pencil, in a variety of ways, which were functional for each child. Table 2 shows the statistical data for force per second, contact area, contact pressure per second (psi per sec), peak force per second (pounds/sec) and peak pressure by second (psi/sec) when holding a pencil before and after the intervention. The raw data is not shown. Significant increases were noted in force per second $(p=0,045)$, and contact area $(p=0,035)$.

\section{Grip system variables when holding a glass}

The contact pressures when holding a glass were highly variable and only 6 of the 11 children could undertake this task before and after the intervention. The remaining children could not hold the glass either before or after the intervention. Contact pressure and area improved after an average of thirtythree treatment sessions and contact area improved after thirty-seven sessions. This data was not statistically significant and not depicted here.

\section{Spasticity (Modified Ashworth grading)}

A visible difference in the fluidity of movement of the upper limb was observed in seven children. One child (Figure $3 \mathrm{a}$ and $\mathrm{b}$ ) showed a marked difference. Figure 3 a shows the upper limb just before weight bearing in the prone position over a foam block and Figure $3 \mathrm{~b}$ shows the upper limb at the end of 15 seconds of weight bearing. The spasticity data using the Ashworth grading are not included. In ten children there was no change in the tone during elbow flexion.

In four children there was a reduction in spasticity during elbow extension, wrist flexion and extension. In three children there was a reduction in spasticity during elbow and wrist extension. The Wilcoxon Rank sum test showed no statistically significant difference in elbow flexion between pre and post-test scores. There was a significant decrease in spasticity during elbow extension between the pre and post-test with $p=0,004$. Significant decrease in spasticity between the pre and post-test values during wrist flexion and extension resulted in $\mathrm{p}=0,026$ and 0,004 respectively.

\section{Discussion}

The results of this study can be summarised as follows; statistically significant increase in contact pressure in both weight-bearing positions. Contact force improved in the prone position and when holding a pencil. Contact area increased 
Table 2: The $p$ values as calculated by the random effects model for the sample $(n=11)$ children when holding a pencil (The highlighted values indicate the significant $p$ values)

\begin{tabular}{|l|l|l|l|l|l|}
\hline Assessment & $\begin{array}{l}\text { Force } \\
(\text { Pounds }) \\
\text { Vs. Time } \\
(\mathrm{Sec})\end{array}$ & $\begin{array}{l}\text { Contact area } \\
\text { Vs Frame } \\
\left(\mathrm{in}^{2}\right)\end{array}$ & $\begin{array}{l}\text { Contact } \\
\text { pressure } \\
(\text { psi) vs. } \\
\text { Time }(\mathrm{sec})\end{array}$ & $\begin{array}{l}\text { Peak Force } \\
(\text { Pounds) } \\
\text { vs. Time } \\
(\mathrm{sec})\end{array}$ & $\begin{array}{l}\text { Peak } \\
\text { pressure } \\
\text { (psi) vs. } \\
\text { Time (sec) }\end{array}$ \\
\hline Pr2 & 0.539 & 0.482 & 0.333 & 0.216 & 0.417 \\
\hline As1 & 0.935 & 0.791 & 0.333 & 0.666 & 0.457 \\
\hline As2 & 0.346 & 0.381 & 0.698 & 0.371 & 0.589 \\
\hline As3 & 0.293 & 0.305 & 0.698 & 0.125 & 0.156 \\
\hline As4 & 0.078 & 0.075 & 0.561 & 0.318 & 0.251 \\
\hline As5 & 0.869 & 0.971 & 0.846 & 0.438 & 0.311 \\
\hline As6 & 0.020 & 0.032 & 0.846 & 0.125 & 0.031 \\
\hline As7 & $\mathbf{0 . 0 4 4}$ & 0.062 & 0.698 & 0.125 & 0.091 \\
\hline Po1 & $\mathbf{0 . 0 4 5}$ & $\mathbf{0 . 0 3 5}$ & 0.438 & 0.136 & 0.091 \\
\hline
\end{tabular}

when holding a pencil. Significant decrease in spasticity was observed during elbow extension, and wrist flexion and extension. This study did not try to quantify strength in the upper extremities. Almost all the published studies on the effects of static or other weight bearing exercises looked at either spasticity (Gracies 2001, Smelt 1989, Kinghorn and Roberts 1996), bone mineralization (Chad et al 1999), grip strength (Hallam and Weindling 1998), or function

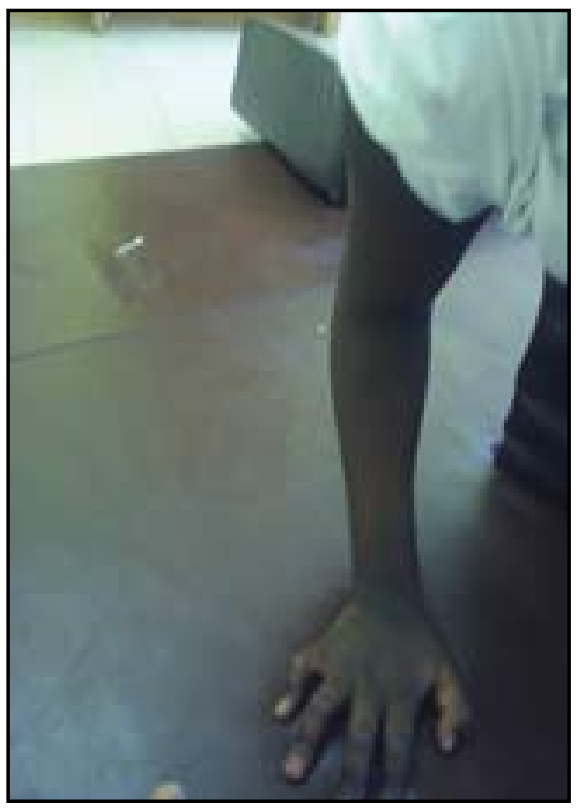

3 a
(Chakerian and Larson, 1993, Beckung and Hagberg 2002, Fedrizzi et al 2003). Very few studies quantified contact area (Smelt 1989, Chakerian and Larson 1993). The current study cannot really be compared with other studies because it looked at whether weight bearing was indeed occurring through the hands and if it did, whether it increased over time and with the intervention program. This would help us determine whether the functional improvements noted

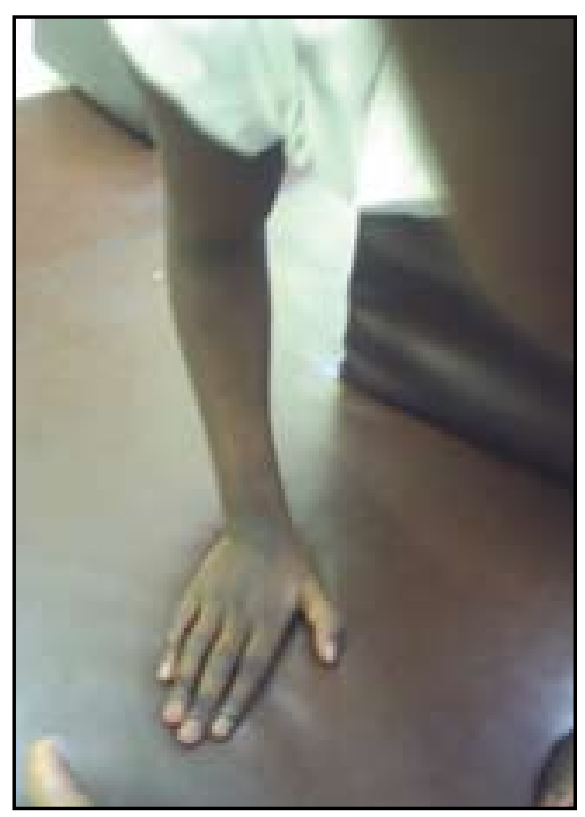

3b

Figure 3: a, Upper limb: Before intervention b, immediately after intervention

(Jayaraman and Puckree 2010) and change in tone can be attributed to the program of weight bearing exercises.

Chakerian and Larson (1993) reported that the increase in hand surface area (in prone) which was significant was not retained post-test which was immediately after twelve sessions of the intervention, which is in contrast to the results of this study (with 35 sessions) where there was a significant increase in contact area post-test in both weight bearing positions and when holding a pencil. However monitoring of the children over a longer period post-test would have revealed information about the sustainability of the achieved responses

Significant improvement in contact pressure, force and area occurred after an average of thirty five treatment sessions. This was reflected in the improved ability of the children to hold a pencil and glass (Table 2). These findings support the improvement in hand opening and prehension skills reported by Chakerian and Larson (1992), Noronha et al (1989) and van Meeteren et al (2007). This implies that in order for weight-bearing exercises to be effective it has to be reinforced in every treatment session and an average of over 30 sessions of exposure to weight bearing is required. This probable explains why Chakerian and Larson (1993) did not find signifi- 
cant results post-test as there were only twelve treatment sessions.

Contact pressure and contact force are important in any discussion of the effectiveness of weight bearing exercises. When muscles are used to maintain a position the effect of body weight and gravity must be counterbalanced. This requires muscular strength. Strength is the capacity of a muscle or group of muscles to exert maximum pressure, or force, against a given resistance in a period of time. If the pressure or force exerted significantly improved, it may imply that the weight bearing improved. Strength was not directly measured in this study

A normal child engages in a variety of weight bearing positions during which it progresses through the normal developmental sequence. A child with cerebral palsy does not engage in these activities (Pin 2007) and therefore placing a child in weight bearing positions may activate dormant sensors in joints and muscles thereby inducing plastic motor changes which may contribute to improved function. During weight bearing through the hands, a stretch is placed on the skin and this mechanical stimulus activates the mechanoreceptors on the ventral surface of the hand stimulating flexion (Paillard and Brouchon 1968). However when the position is maintained, inhibition of the stretch reflex occurs and relaxation of the wrist and elbow flexors occurs (Gracies 2001). The fact that weight bearing causes hand opening can be verified by the fact that there was an increase in contact area in this study and the associated observed effects on muscle tone. Chakerian and Larson (1993) and Smelt's (1989) follow up showed no long- term improvement in hand contact surface area.

Weight bearing exercises resulted in a significant decrease in spasticity in the wrist flexors and extensors and in elbow flexors. A decrease in tone after weight bearing was reported by Smelt (1989) reported a significant decrease in tone after using inhibitive weightbearing mitts in his study. Kinghorn and Roberts (1996) who used weight-bearing splints found minimal changes in tone. These studies also found improvements in function. These reports support the findings of the present study in which a significant improvement in the contact area was noted through quantified data. This change in contact area was supported by a statistically significant decrease in tone, which supports the work of Smelt (1989). The present study did not follow up the participants to determine whether the reduction in tone was maintained.

The effects of weight bearing on spasticity are explained by the Bobath/ Neuro-developmental theory. The use of 'tone influencing patterns' is used to normalize tone (Bobath and Bobath 1980; Davis 1985). When in a weight bearing position (quadruped for example), the child's upper extremity is in ninety degrees flexion with neutral rotation at the shoulder, extension at the elbow, pronation of the forearm, extension at the wrist and extension at the metacarpo and inter-phalangeal joints of the fingers. The thumb is abducted and away from the plane of the hand. The majority of the children in this sample had a predominant flexor pattern in the upper limb. Weight bearing in different positions could be considered as 'tone influencing' to help to counter the flexor pattern according to the Bobath approach. It is likely that because the elbow and the wrist were maintained in extension, there was a reduction in tone in the elbow and wrist flexor muscles. The weight bearing exercises could have also helped to bring about a balance of flexor and extensor tone in the upper extremities. This balance between flexor and extensor tone, which allows for a coordinated movement is severely compromised in children with cerebral palsy (Danella and Voglte 1992).

Clinically the physiological effects of weight bearing exercise can be capitalized to optimize task specific training of the upper limb through the positive effects like reduction in tone and increase in hand contact surface area (Chakerian and Larson 1993) and range of motion (Smelt 1989; Pin et al 2006). However long term maintenance in tone reduction still needs to be determined.

The measurement of grip strength and function in normal and impaired individuals is receiving attention in the literature (Svensson et al 2008, Hallam and Weindling 1998). In this study the specific variables were monitored to determine whether an increase in weight borne through the hands had any effect on them. No attempt was made to measure strength. While the physiological mechanisms for the improvements in contact area and pressure when holding a pencil and tumbler can only be speculated, a need for more basic studies is indicated.

\section{Limitations}

The quasi experimental pre-post-test design should have been supplemented with multiple pre-test and post-test monitoring to both ensure a stable baseline and retention of effects gained as a result of the intervention. In this study it was possible to only do two pre-tests and one post-test assessment due to nonavailability of the children due to various reasons. It would have been ideal to have more pre-tests. The choice of statistical test based on assumptions about the data allowed for incorporation of adjustment techniques to control for this threat to internal validity as best as possible.

In a study of this nature the other factors such as play, home and school activities could have had an affect on the outcome. To protect against this, extraneous variables like what the child did during physiotherapy and occupational therapy was regulated as mentioned in the preceding sections. A control group would have allowed for a comparison. Information gathered from parents and caregivers regarding activities outside the intervention showed that this was not a threat to the internal validity of the design.

The learning effects of repeated testing may also have an impact on the results but if testing influences responses, these effects are likely to have been similar for all the children. The choice and the nature of instrumentation in this study have belied this effect to a large extent. In addition, statistical tests indicate that there was no significant difference between the pre-tests therefore this threat to validity was controlled to an extent. Even though the average age of the children was 12.66 years, changes as a result of normal maturation can not be ruled out (Sankar and Mundkur 2005) 
Finally it will not be possible to generalize the results of this study to a wider population due to the fact that the sample size was small, and the subjects were not chosen randomly. However, the nature of the participant population may make randomisation extremely difficult to achieve.

\section{References}

Bovend'Eerdt TJ, Newman M, Barker K, Dawes H, Minelli C, Wade DT 2008 The effects of stretching in spasticity: a systematic review. Archives of Physical Medicine and Rehabilitation 89:1395-1406

Beckung E, and Hagberg G 2002 Neuroimpairments, activity limitations and participation restrictions in children with cerebral palsy. Developmental Medicine and Child Neurology 44: 309-316

Bobath B, Bobath K 1980 A Neurophysiological Basis for the Treatment of Cerebral Palsy. Clinics in Developmental Medicine 75:28-98

Boehme R 1993 Management of the hand in cerebral palsy. Teamtalk 2: 1-15

Bohannon RW, Smith MB 1987 Inter-rater reliability of a modified Ashworth scale of muscle spasticity. Physical Therapy 67: 206-7

Chad KE, Bailey DA, Mc Kay HA, Zello GA, Snyder RE 1999 The effect of a weight bearing physical activity programme on bone mineral density. Pediatrics 135:115-7

Chakerian DL, Larson MA 1993 Effects of upper-extremity weight-bearing on handopening and prehension patterns in children with cerebral palsy. Developmental Medicine and Child Neurology 35:216-29

Danella E, Vogtle L 1992 Neurodevelopmental treatment for the young child with cerebral palsy. In Case-Smith J, Pehoski C. Development of the hand skills in the child. American Occupational Therapy Association. ppl.91-110, United States

Davis JZ 1985 Neurodevelopmental treatment: The Bobath approach to the treatment of adult hemiplegia, In Pedretti LW (ed): Occupational Therapy: Practice Skills for Physical Dysfunction, ppl 217-226, London, Mosby

Fedrizzi E, Pagliano E, Andreucci E, Oleari G 2003 Hand function in children withy hemiplegic cerebral palsy, prospective follow up and functional outcome in adolescence 45: 85-91
Fleuren JFM, Voerman GE, Catelijne V. ErrenWolters CV, Snoek GJ, Rietman JS, Hermens HJ, Nene AV, 2010 Stop using the Ashworth Scale for the assessment of spasticity. Journal of Neurology Neurosurgery and Psychiatry 81: 46-53.doi:10.1136/jnnp.2009.177071

Gandevia SC, McCloskey 2000 In: Collins DF, Refshauge KM, Gandevia SC. Sensory integration in the perception of movements at the human metacarpophalangeal joint. Journal of Physiology 529:505-515

Gracies J-M. 2001 Pathophysiology of impairment in patients with spasticity and use of stretch as a treatment of spastic hypotonia. Physical Medicine Rehabilitation Clinics in North America 12: $747-768$

Hallam P, Weindling M 1998 The objective measurement of grip strength in children with cerebral palsy Pediatric Research 44: 448

(http://en.wikipedia.org/wiki/Muscle)

Jan M, Katja W, Daniel M, Kay G, Christian Z, Rainer K, Marcus P 2005 Reliability of the Modified Tardieu Scale and the Modified Ashworth Scale in adult patients with severe brain injury: a comparison study. Clinical Rehabilitation 19: 751-759

Jayaraman P, Puckree T 2010 The effect of upper extremity weight bearing on upper extremity function in children with hemiplegic type of cerebral palsy, South African Journal of Physiotherapy: in press

Kinghorn J, Roberts G 1996 The effect of an inhibitive weight-bearing splint on tone and function: a single-case study. American Journal of Occupational Therapy 50:807-15

Noronha J, Bundy A, Groll J 1989 The effect of positioning on the hand function of boys with cerebral palsy. American Journal of Occupational Therapy 43: 507-512

Odding E, Roebroeck ME, Stam HJ The epidemiology of cerebral palsy: incidence, impairments and risk factors. Disability and Rehabilitation 28: 183-191

O’ Sullivan SB, Schmitz TJ 2001 Physical rehabilitation Assessment and Treatment, ppl 177-212, 363-410 Jaypee Brothers, Baltimore

Paillard J, Brouchon M 1968 Active and passive movements in the calibration of position sense. In Freedman S.J (Ed), The neuropsychology of spatially oriented behaviour, ppl. 37-55, Dorsey Press, Homewood III
Pin T, Dyke P, Chan M 2006 The effectiveness of passive stretching in children with cerebral palsy. Developmental Medicine and Child Neurology 48:855-862

Sankar C and Mundkur N 2005 Cerebral palsydefinition, classification, etiology and early diagnosis Indian Journal of Pediatrics 72: 865-868

Smelt HR 1989 Effect of an inhibitive weightbearing mitt on tone reduction and functional performance in a child with cerebral palsy. Paediatrics 9:53-80

Svensson E, Waling K, Hager-Ross C 2008 Grip strength in children:Test-retest reliability using Grippit. Acta Pediatrica 97: 1226-1231

Tekscan Research User Manual 2006 www. tekscan.com

van Meeteren J, van Rijn RM, Selles RW, Roebroeck ME, Stam HJ 2007 Grip strength parameters and functional activities in young adults with unilateral cerebral palsy compared with healthy subjects. Journal of Rehabilitation Medicine 39:598-604a 